\title{
BMJ Open Effectiveness of a guided online mindfulness-focused intervention in a student population: Study protocol for a randomised control trial
}

\author{
Dana Schultchen (D) , ${ }^{1}$ Ann-Marie Küchler (D) , ${ }^{2}$ Christine Schillings (D) , ${ }^{1}$ \\ Felicitas Weineck (D) , ${ }^{1}$ Alexander Karabatsiakis (D) , ${ }^{3}$ David D. Ebert (D) , 4 \\ Harald Baumeister (D) , ${ }^{2}$ Olga Pollatos (D) ${ }^{1}$
}

To cite: Schultchen $\mathrm{D}$, Küchler A-M, Schillings C, et al. Effectiveness of a guided online mindfulnessfocused intervention in a student population: Study protocol for a randomised control trial. BMJ Open 2020;10:e032775. doi:10.1136/ bmjopen-2019-032775

- Prepublication history for this paper is available online. To view these files, please visit the journal online (http://dx.doi. org/10.1136/bmjopen-2019032775).

Received 04 July 2019 Revised 07 February 2020 Accepted 04 March 2020

Check for updates

C Author(s) (or their employer(s)) 2020. Re-use permitted under CC BY-NC. No commercial re-use. See rights and permissions. Published by BMJ.

${ }^{1}$ Department of Clinical \& Health Psychology, Ulm University, Ulm, Baden-Württemberg, Germany ${ }^{2}$ Department of Clinical Psychology \& Psychotherapy, Ulm University, Ulm, BadenWürttemberg, Germany

${ }^{3}$ Clinical Psychology, University of Innsbruck, Innsbruck, Tyrol,

Austria

${ }^{4}$ Department of Clinical, Neuro\& Developmental Psychology, Vrije Universiteit Amsterdam, Amsterdam, Netherlands

Correspondence to Dr Dana Schultchen; dana.schultchen@uni-ulm.de

\section{ABSTRACT}

Background Previous studies show that university students experience higher psychological stress than the general population, resulting in increased vulnerability for mental disorders for the student population. Online mindfulness interventions will be delivered to students as a potentially promising and more flexible approach compared to face-to-face interventions with the aim of improving their mental health. This study purposes to investigate the effectiveness of a guided online mindfulness-focused intervention for university students by using both self-reported and psychobiological measures.

Methods and analyses In this multicentre, two-armed randomised controlled trial with a parallel design, a guided version of the online mindfulness-focused intervention 'StudiCare Mindfulness' will be compared with a waitlist control group. In total, 120 participants will be recruited at different universities (of Applied Sciences) in (Neu-) Ulm. Data will be assessed prior to randomisation, after eight weeks (post-intervention) and six months after randomisation (follow-up). The primary outcome measure is mindfulness. The secondary outcome measures include depression, anxiety and stress levels, well-being, interoceptive sensibility, emotion regulation and alexithymia. Psychobiological parameters comprise interoceptive accuracy, hair cortisol and FKBP5 genotype. Sociodemographic variables, treatment expectations, side and adverse side effects, as well as intervention satisfaction and adherence will be assessed. All data analyses will be conducted according to the intention-totreat principle.

Ethics and dissemination All study procedures have been approved by the Ethics Committee of Ulm University (application No. 48/18). The findings will be disseminated widely through peer-reviewed publications and conference presentations.

Trial registration number DRKS00014701.

\section{BACKGROUND}

Stress is highly prevalent among university students. Previous studies showed that compared to the general population, students have significantly higher stress levels. ${ }^{1-3}$ The
Strengths and limitations of this study

- 'StudiCare Mindfulness' is an online mindfulnessfocused intervention programme with the aim to increase mindfulness and simultaneously decrease stress levels in order to reduce mental disorders in university students.

- This study considers psychobiological parameters in addition to the common participants' self-report data prior to randomisation as well as eight weeks and six months after randomisation.

- A follow-up measurement six months after randomisation is administered.

- Because of the use of psychobiological parameters, the study will only be conducted at universities (of Applied Sciences) in (Neu-)Ulm which could reduce generalisability.

increased clinical levels of stress in university students have been linked to a range of stressors such as new experiences and challenges in addition to new social relationships, academic pressures and exams. ${ }^{24-7}$ Moreover, such high stress levels have the potential to trigger mental illness such as anxiety and/ or depression or to exacerbate a pre-existing mental health condition. ${ }^{8-14}$ For example, Auerbach et $a l^{15}$ found in an international WHO survey that more than $20 \%$ of university students reported a mental disorder. However, it should be noted that $83 \%$ of these students had a mental illness onset before commencing their studies. Similar results were found in another survey, indicating that $23 \%$ of university students met the criteria for a mental disorder. ${ }^{16}$ The development of a mental disorder is related to a more severe and chronic disease trajectory, a higher risk of developing comorbidities, decreased academic performance, as well as 
an increased probability for dropouts during the university career. ${ }^{5} 917-19$

Accordingly, it is crucial to prevent elevated stress levels to reduce the risk of university students developing a mental health disorder. In this context, previous studies revealed that most university students do not use faceto-face interventions and do not seek professional help, although most of the universities provide free health and counselling services. ${ }^{8} 14$ 20-25 Prohibitive factors to accessing services reported by university students included: lack of time, fear of stigma, the preference to get help and support from family or friends as well as lack of knowledge regarding available services at the university. Thus, internet-based and mobile-based psychological interventions (IMIs) may offer a promising approach to close the gap between these barriers and to provide additional advantages (eg, no need for therapist availability, low-threshold access, stigma-reduction, cost-effectiveness as well as flexibility regarding time and place). ${ }^{21} 2226-30$ Emerging evidence from different studies has also demonstrated that online interventions can be as effective as face-to-face programmes in healthy and clinical populations. ${ }^{31-33}$ Furthermore and most importantly, nowadays young people grow up in a digital world and show a preference for using the internet and smartphones daily. ${ }^{34-36}$ They are also searching for health information online. ${ }^{37}$ However, a study with an Australian sample (mean age 36.6 years) showed that $77 \%$ prefer face-to-face interventions. ${ }^{38}$ In another study by Ryan and colleagues,${ }^{25}$ findings indicate that nearly $50 \%$ of university students (mean age 23.7) in Australia have a preference for online interventions. Consequently, the age range and the context seem to be crucial for understanding the preferences of the type of therapy delivery in different populations. ${ }^{25}$ Moreover, Stallman and Kavanagh ${ }^{39}$ as well as Ebert $e t a l^{26}$ observed that university students show a high acceptance for and usability of online interventions. A growing body of research found that online interventions are helpful to improve mental health conditions. ${ }^{26}{ }^{40-45}$ These effects can be enhanced by therapeutic guidance, meaning that participants receive additional support from an expert, either online or face-to-face while receiving the online intervention. ${ }^{6}{ }^{6}$

One opportunity to improve mental and physical health is mindfulness. Mindfulness is the awareness of the present moment in an open, accepting and nonjudgmental way with the focus on internal bodily signals (eg, ones' breathing and other bodily sensations ${ }^{47-49}$ ) as well as external stimuli (eg, sounds, pictures, behaviour ${ }^{50}$ ). Several studies found positive effects of a mindfulnessbased intervention on mental and physical health conditions, independent of whether these included healthy or clinical participants. ${ }^{51-59}$ Furthermore, Wahbeh et $a l^{59}$ observed in their study sample that there was a preference for online mindfulness-based interventions compared to group or one-by-one interventions. As there are clear benefits of mindfulness-based interventions as well as online interventions such as e-health programmes, it seems timely to combine these approaches to reduce stress and, therefore, to improve mental health in a student population.

Numerous studies ${ }^{436-63}$ and meta-analyses ${ }^{64}{ }^{65}$ found evidence for the efficacy of online mindfulness-based interventions with the focus on self-reported health variables (eg, depression, anxiety, and stress). For example, Spijkerman et $a l^{64}$ compared 15 randomised control trials and showed small to medium effect sizes regarding the reduction of anxiety ( $\mathrm{g}=0.22 ; 95 \%$ CI: 0.05 to 0.39 ), improvement of depression ( $\mathrm{g}=0.29 ; 95 \%$ CI: 0.13 to 0.46 ), well-being ( $\mathrm{g}=0.23 ; 95 \%$ CI: 0.09 to 0.38 ), and mindfulness ( $\mathrm{g}=0.32 ; 95 \%$ CI: 0.23 to 0.42 ) in healthy samples as well as samples with mental disorders. Especially for stress reduction, a large effect was shown $(\mathrm{g}=0.51 ; 95 \% \mathrm{CI}: 0.26$ to $0.75)$. Similar results were found in another meta-analysis conducted by Jayewardene et al..$^{65}$ The authors compared eight studies focusing on the effects of online mindfulness interventions in non-clinical populations with subclinical mental health conditions ( $\mathrm{g}=0.28$ to $0.42 ; 95 \%$ CI: 0.15 to 0.67 ). Moreover, these results showed further improvements in mental health at follow-up ( $\mathrm{g}=0.47$ to 0.70; $95 \%$ CI: 0.14 to 1.13 ). Even though these findings are promising, self-report data might substantially overestimate the effectiveness of interventions. Hence, the field should move forward to include more objective data to verify the promising results by including assessments of psychobiological variables.

Until now, there are no studies regarding the effectiveness of online mindfulness-focused training on psychobiological variables which represent objective markers of mental health conditions. Such variables are not influenced by social desirability, memory problems or a conscious perception. ${ }^{66}$ Consequently, psychobiological data provide additional markers to complement the self-reported data and should, therefore, be included in mindfulness and stress-related intervention studies. In this study, we will include psychobiological measurements of interoceptive accuracy as well as cortisol and dehydroepiandrosterone (DHEA). Interoceptive accuracy represents the behavioural assessment of an individual's ability to perceive internal bodily changes which is mostly assessed via the heartbeat perception task. ${ }^{67}$ Moreover, interoceptive accuracy is associated with other health-related variables such as emotion perception and regulation, alexithymia, stress, depression, anxiety symptoms and eating behaviour ${ }^{68-73}$ and can be influenced by the mentioned health-related variables. Recent studies focusing on interoceptive accuracy showed mixed results regarding the impact of different offline mindfulness interventions. ${ }^{74-76}$

Two biological indicators of the body's physiological stress response are cortisol and DHEA. While cortisol is a steroid hormone released by the hypothalamic-pituitaryadrenal (HPA) axis in response to stress, ${ }^{77}$ DHEA represents an endogenous steroid hormone on the stress response that can antagonise the effect of cortisol. ${ }^{78}$ To assess long-term effects of stress, collecting hair samples 
is superior to fluid biomaterial (eg, saliva, blood) because hair samples reflect stress levels of weeks or even months and are not influenced by acute stress before or during the measurements, the body's circadian rhythm or hormone levels. ${ }^{79-82}$ Accordingly, the ratio between cortisol and DHEA seems to be important. There is only one study showing positive effects of an 8-week body-scan training (one approach of the mindfulness-based stress reduction programme) on cortisol, DHEA and the ratio. ${ }^{83}$ Several other studies reveal inconsistent results concerning the effect of mindfulness interventions on stress parameters assessed via saliva or plasma cortisol. ${ }^{84-89}$ Moreover, there is no other evidence in previous research of a mindfulness training on DHEA. Besides the study of Schultchen $e t a l^{33}$, some studies measured the sulfated form of DHEA (DHEA-S) and found no effect on DHEA-S after an 8-week mindfulness-based stress programme in a population diagnosed with cancer. To combine both stress markers, different researchers suggest the cortisol/DHEA ratio as a parameter for the endocrine imbalance of HPA regulation. ${ }^{90-94}$ Comparable to DHEA, there is only the study of Schultchen et $a l^{83}$ examining the change of the ratio through the body scan and another study by Cruess $e t$ $a \ell^{33}$ that has investigated the cortisol/DHEA-S ratio. The study by Cruess $e t a \ell^{3}$ indicated that men diagnosed HIV positive had an improved ratio after participating in a cognitive-behavioural stress management programme in comparison to a waitlist control group. To sum up, studies examining psychobiological parameters in mindfulnessbased programmes are very sparse, though there are some promising results. Nonetheless, such investigations are essential to characterise the long-term effects of mindfulness on psychobiological processes.

Another interesting marker is the gene FKBP5 coding for FK506 binding protein 51 (FKBP51). FKBP51 is a co-chaperone of the glucocorticoid receptor, changing its affinity for cortisol and therefore influencing the reactivity of cortisol-mediated stress signalling in the body. Compared to $\mathrm{C}$-allele carriers (wild type) at position rs1360780, individuals with the T-allele show a higher risk for depression and less clinical responsiveness to antidepressant treatment. ${ }^{95}$ Also, T-allele carriers show more pronounced changes in hair cortisol levels with increasing childhood maltreatment compared to C-allele carriers, demonstrating a gen $\mathrm{x}$ environment interaction with a dose-response relationship between adverse childhood experiences, a strong predictor for late-life depression and steroid hormones of the body's stress response. ${ }^{96}$ In comparison to the other psychobiological stress markers, FKBP5 is usually assessed once because there is no fluctuation. Consequently, this marker will be included as a covariate variable.

An additional focus of the present trial is the effectiveness of guidance during the online mindfulness-focused intervention. Research in this context provides evidence that guidance enhances the efficacy of online interventions on health-related variables. ${ }^{6497}$ In the context of an online mindfulness training for students, only the study of
Mak $e t a l^{61}$ provided telephone or email support without a control group.

Taken together, we hypothesise that

1. The primary outcome mindfulness will be improved after the intervention in comparison to a waitlist control group.

2. The secondary outcomes of depression, anxiety, stress levels, interoceptive sensibility, emotion regulation, and alexithymia will also be improved. We assume similar results for the psychobiological variables, including interoceptive accuracy (assessed via the heartbeat perception task) as well as cortisol and DHEA levels in hair.

Further, it should be noted that outcomes can be influenced by various covariates. For example, interoceptive accuracy can be influenced by emotion regulation, alexithymia or depression and anxiety symptoms. ${ }^{68}$ 71-73 Therefore, we will test for potential effect-modifying variables on an exploratory level. Lastly, we intend to explore and analyse the participants' satisfaction, adherence, and acceptance of the intervention.

\section{METHODS}

\section{Study design}

This project is a two-armed randomised controlled trial with a parallel design comparing the effectiveness of a guided version of the online, preventive mindfulness intervention 'StudiCare Mindfulness' to a waitlist control group (see figure 1 for flow chart). The research aims to examine the effectiveness of 'StudiCare Mindfulness' on different self-reported and psychobiological healthrelated parameters at three measurement points (before the intervention as well as eight weeks and six months after randomisation). Moreover, the individuals' adherence, acceptance, and satisfaction are measured to identify possibilities to improve the intervention. Participants of both the control and the intervention group have access to treatment as usual. Thus, participants can use other support or treatment options that will be monitored in order to control for potential confounding effects.

Two departments of the Ulm University are involved in the project, including the Department of Clinical and Health Psychology and the Department of Clinical Psychology and Psychotherapy. It should be noted that this is a cooperation project. Besides the presented study in this protocol, there is another parallel mindfulness trial, investigating the effectiveness of a 'guidance on demand' and an unguided version of 'StudiCare Mindfulness' in comparison to a waitlist control group. ${ }^{98}$

The present study is conducted and will be reported according to the Consolidated Standards of Reporting Trials 2010 Statement ${ }^{99}$ and the guidelines for executing and reporting internet intervention research. ${ }^{100}$ The study protocol complies with recommendations of the Standard Protocol Items: Recommendations for Interventional Trials 2013 Checklist for clinical trial protocols. ${ }^{101}$ 


\section{Inclusion Criteria:}

- Age of 18 years or above

- Enrolled in university or college

- Sufficient knowledge of the German language

- Internet access

- Moderate or low mindfulness $(\mathrm{FMI}<37)$
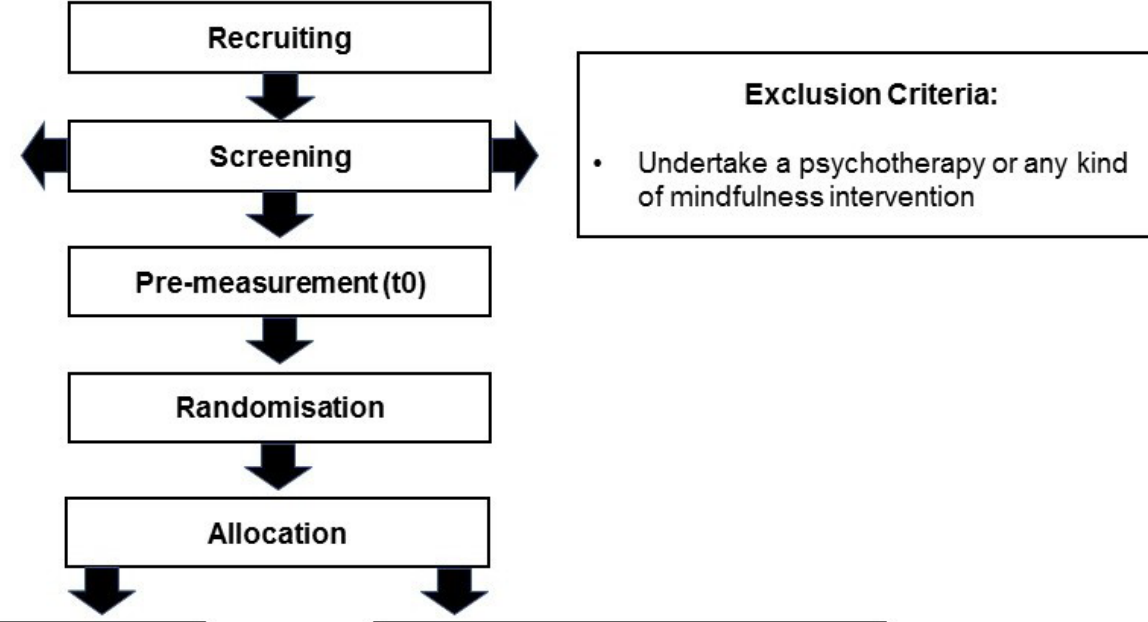

Guided intervention group

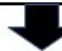

Post-measurement (t1): Eight weeks after randomization

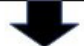

Follow-up (t2): Six months after randomization

Figure 1 Flow chart of the study design. FMI, Freiburg Mindfulness Inventory.

The 'StudiCare Mindfulness' trial is carried out as part of the 'StudiCare' project funded by BARMER, a cooperation of the Universities of Erlangen-Nuremberg and Ulm. The overall project aims to improve college university students' well-being by evaluating their mental health in longitudinal panel surveys as well as developing and offering a broad assortment of internet-based interventions for psychological and behavioural issues (such as procrastination, examination anxiety, physical activity). It is embedded in the 'World Mental Health Survey International College Student' project ${ }^{102}$ and the 'Caring Universities' project. ${ }^{103}$

\section{Patient involvement}

University students as target end users of 'StudiCare Mindfulness' were involved in the development process of the intervention. They will also be involved in the conduct and the reporting of the research, however, not in their role as end users but in their role as scientists. The public will be informed about the results via several ways, among other publications, lectures and workshops.

\section{Eligibility criteria}

Participants providing written informed consent and fulfilling the following inclusion criteria for participation will be applied: (a) age of 18 or above, (b) enrolled at Universities (of Applied Sciences) in Ulm or NeuUlm, (c) sufficient knowledge of the German language, (d) internet access, (e) moderate to low mindfulness (Freiburg Mindfulness Inventory $(\mathrm{FMI})<37$ ); this cut-off was chosen as it represents the medium value of the FMI in subjects from the general population. ${ }^{104}$ Participants are excluded from the study if they currently undertake psychotherapy or any mindfulness intervention. To investigate if participants are eligible, they have to fill out a screening questionnaire.

\section{Setting/recruitment}

Recruitment has started in May 2018 and will continue until the target sample size of 120 participants will be reached. Participants are recruited from particular different universities in (Neu-) Ulm, including Ulm University, Ulm University of Applied Sciences and Neu-Ulm University of Applied Sciences because psychobiological parameters have to be assessed on site. The following recruiting channels are used: email, flyers and posters, social media, student unions, and student counselling services. University students get information about the 'StudiCare' offers and a link to the homepage (www.studicare.com), where they can get further information and register for the IMIs. Once registered, they receive an email with a link to the screening questionnaire. Depending on the location of their university, participants are either allocated to Kuechler $e$ t $a l_{\text {s }}$ trial $^{98}$ (all other cooperating universities in Germany, Austria and Switzerland) or to the present study (students from different universities (of Applied Sciences) in Ulm and Neu-Ulm), as psychobiological tests demand actual on-site attendance. Once the screening is completed, participants receive an email with further information on the study as well as an informed consent form which they are required to send back to the study staff via email. When written consent is obtained and the pretest completed, another email is sent to inform 
participants about their group allocation (intervention or waitlist control group). If participants are part of the intervention group, they will also receive a link to the intervention. Participants are informed that 'StudiCare Mindfulness' cannot replace psychotherapy and are recommended to seek counselling/psychotherapy in case of distinctive mental health problems. Additionally, they are provided with alternative treatment options and contact details (this information is also given to participants who do not meet the selection criteria).

\section{Randomisation}

After completing the baseline assessment, participants are randomly allocated to one of two study groups (guided intervention vs. waitlist control group) by an independent member of Ulm University not otherwise involved and therefore blinded to all processes of the study. Via an automated, online-based randomisation programme (www.sealedenvelope.com), permuted block randomisation is performed with an allocation ratio of 1:1 and variable block sizes of 2 and 4 (randomly arranged).

\section{Intervention}

The online mindfulness-focused intervention consists of seven weekly, target-group-specific modules of approximately $60 \mathrm{~min}$. each. Additionally, two booster sessions are activated four and twelve weeks after completion of the seventh module in order to enhance sustainability of the intervention effects. These booster sessions include a summary of the seven previous modules. Our aim was to give participants the possibility to collect a repertoire of useful methods. Beyond that, already completed sessions are accessible and can be repeated as often as participants wish to. All modules contain information on stress, wellbeing, and mindfulness with a weekly alternating focus on different topics such as interoception, dysfunctional and beneficial thinking, values, and goals. Whereas these contents are provided via texts, images, and interactive elements (such as quizzes or conditional content), the focus of the intervention lies on the regular practice of mindfulness exercises such as body scans, breathing meditations, or mindful yoga. Therefore, each module includes downloadable audio files as well as mindfulness diaries to be completed in weekly homework assignments. At the beginning of each module, participants are encouraged to reflect on their assignments and also on their most and least mindful moments of the week. The content of the intervention is mainly based on Acceptance and Commitment Therapy ${ }^{105}$ as well as on mindfulness-based stress reduction ${ }^{106}$ and also includes some elements of stress management ${ }^{107}$ and cognitive-behavioural therapy. We summarised the different methods as one mindfulnessfocused intervention.

The intervention's primary goal is to increase the student participants' mindfulness and psychological flexibility in order to enable them to manage their daily hassles flexibly. Furthermore, the intervention was mainly developed by the Department of Clinical Psychology and
Psychotherapy, Ulm University. Its efficacy has already been demonstrated in a randomised controlled trial. ${ }^{108}$ Based on participants' feedback, the different sessions were adapted and further refined in cooperation with the Department of Clinical and Health Psychology, Ulm University. Moreover, the two weekly sessions ('Mindfulness body perception' and 'Body and sense') were also extended. Table 1 summarises the topics and contents of each module. The intervention is available for participants on the Minddistrict platform (www.minddistrict. com), a company specialised in the provision of internetbased health interventions. Participants can get access to the platform via their personal username and password on a $24 / 7$ basis. All transferred data will be secured based on ISO27001 and guidelines NEN7510.

\section{Guidance and promotion of adherence}

Participants randomised to the intervention will receive support by an e-coach. They can contact their e-coach in case of questions or if they wish to get feedback for any of their completed modules. E-coaches are trained and supervised psychologists (by HB, AMK) that give semi-standardised feedback within two working days after participants have finished their modules, following an e-coach manual. Whenever participants have questions or wish to get feedback on their module input, they can contact their personal e-coach via the Minddistrict platform's message function. At the beginning of the intervention, each participant receives a welcoming message in which their e-coach introduces himself. Additionally, the first module explicitly highlights the possibility to contact the e-coach at any time. The feedback content is specific to the participants' assignments in order to support treatment adherence. It also includes positive reinforcement to encourage and motivate the participants to continue the intervention. E-coaches are instructed to document any responses to questions or the given feedback. This will enable the evaluation of actual usage of a guided intervention by participants.

\section{Control condition}

Participants in the waitlist control group have unrestricted access to any usual treatment options. They receive an information leaflet informing them about alternative support options such as university counselling services, psychotherapy or helplines as well as the advice to seek help in case their well-being declines. Six months after randomisation, participants of the control condition receive the unguided version of the intervention.

\section{Assessments and outcomes}

Assessments take place before ( $\mathrm{t} 0$; pre-measurement) as well as after eightweeks (t1; post-measurement) and six months (t2; follow-up) after randomisation. All selfreport data are collected using the online survey platform 'Unipark' (www.unipark.de). Furthermore, participants come to the laboratory of the Department Clinical and Health Psychology to collect the psychobiological data 
Table 1 Overview of the different topics and contents of each module

\begin{tabular}{|c|c|c|}
\hline Module & Aims and content & Examples of exercises and assignments \\
\hline 1. Being in the here and now & Introducing the concept of mindfulness & $\begin{array}{l}\text { Reviewing most and least mindful moments of the day; } \\
\text { practising body scan; taking mindful walks }\end{array}$ \\
\hline 3. A new perspective on stress & $\begin{array}{l}\text { Distancing oneself from stress-inducing } \\
\text { thoughts }\end{array}$ & $\begin{array}{l}\text { Identifying former ways of coping with stress; learning } \\
\text { techniques to challenge automatic thoughts; meditation } \\
\text { exercise }\end{array}$ \\
\hline $\begin{array}{l}\text { 5. What makes your life } \\
\text { valuable? }\end{array}$ & $\begin{array}{l}\text { Identifying one's values and pursuing one's } \\
\text { goals }\end{array}$ & $\begin{array}{l}\text { Writing a speech for one's 70th birthday; setting and } \\
\text { pursuing goals with the SMART technique; meditation } \\
\text { exercise }\end{array}$ \\
\hline $\begin{array}{l}\text { 7. Training your body and } \\
\text { senses }\end{array}$ & $\begin{array}{l}\text { Exercising the ability to enjoy and getting } \\
\text { acquainted with the practice of yoga }\end{array}$ & $\begin{array}{l}\text { Mindful chocolate eating exercise; mindful yoga } \\
\text { exercises }\end{array}$ \\
\hline $\begin{array}{l}\text { Booster session } 1 \\
\text { (four weeks after completion of } \\
\text { module } 7 \text { ) }\end{array}$ & $\begin{array}{l}\text { Repeating module } 1 \text { to } 3 \text { and different } \\
\text { mindfulness exercises }\end{array}$ & $\begin{array}{l}\text { Choosing favourite mindfulness exercises; setting goals } \\
\text { for their implementation }\end{array}$ \\
\hline $\begin{array}{l}\text { Booster session } 2 \text { (twelve } \\
\text { weeks after completion of } \\
\text { module } 7 \text { ) }\end{array}$ & $\begin{array}{l}\text { Repeating modules } 4 \text { to } 7 \text { and ensuring } \\
\text { long-term integration of mindfulness into } \\
\text { daily life }\end{array}$ & $\begin{array}{l}\text { Reviewing pursuit of goals in the last two months; } \\
\text { identifying potential barriers and developing solutions }\end{array}$ \\
\hline
\end{tabular}

(heartbeat perception task, hair samples for cortisol and DHEA as well as buccal cell swabs for the collection of DNA from buccal mucosa for genotyping FKBP5). Biological samples are processed in the Department of Clinical and Biological Psychology under the direct supervision of AK. See table 2 to get an overview of the different outcome measures and assessment time points. Participants receive $€ 20$ or 3 course credits as compensation for the laboratory assessment. Importantly, they do not obtain any compensation for participation in the online intervention.

\section{Primary outcome: Mindfulness}

The 14-item short version of the Freiburg Mindfulness Inventory $(\mathrm{FMI})^{104109}$ is used to derive a mindfulness score. The FMI consists of a 4-point Likert scale ranging from $1=$ ='rarely' to $4=$ 'almost always'. The short version is sensitive to changes and appropriate for investigating subjects without meditation experience. ${ }^{104}$ In a study by Heidenreich et $a l^{10}$ a high internal consistency with a Cronbach's Alpha of 0.84 was shown.

\section{Secondary outcomes}

\section{Depressive symptoms}

The depression module of the Patient Health Questionnaire (PHQ-9) ${ }^{111}$ comprises nine items that are rated on a 4-point Likert scale ( $0=$ 'not at all' to 3='nearly every day'). The PHQ-9 is a widely used depression screening that has demonstrated validity and good diagnostic properties (sensitivity of 0.95 and specificity of 0.84 ) and internal consistency $(\alpha=0.89){ }^{112}$

\section{Anxiety}

The Generalized Anxiety Disorder Questionnaire (GAD$7)^{113}$ consists of a 7-item anxiety scale ranging from 'not at all' $(=0)$ to 'nearly every day' $(=3)$ and is used to screen for generalised anxiety disorders. Evaluations of the questionnaire show a sensitivity of 0.89 , specificity of 0.82 and a good test-retest reliability (intraclass correlation $=0.83$ ). The GAD-7 has been identified as a reliable and valid measure of anxiety in the general population with Cronbach's Alpha of $0.89 .^{114}$

\section{Stress}

The Short Form Perceived Stress Scale (PSS-4), derived from the Perceived Stress Scale, ${ }^{115}$ is used to measure the participant's perceived stress as the degree to which situations in one's life are rated as stressful (scale ranging from $0=$ 'never' to $4=$ ='very often'). The psychometric properties of the PSS-4 are acceptable and reliable across cultures, with Cronbach's Alpha of 0.77. ${ }^{116}$

\section{Well-being}

The well-established 5-item WHO Well-Being Index $(\mathrm{WHO}-5)^{117}$ is used to assess subjective psychological well-being. The response scale refers to the frequency of relevant feelings over the past two weeks ranging from 'at no time' $(=0)$ to 'all of the time' $(=5)$. With a sensitivity of 0.86 and specificity of 0.81 , WHO- 5 is a screening tool for depression which has been demonstrated among several clinical studies. Applicability across study fields and clinical validity is very high. ${ }^{118}$ 
Table 2 Summary of the outcome assessments and assessment time points

\begin{tabular}{|c|c|c|c|c|c|}
\hline Variables & Measurement & Screening & TO & T1 & T2 \\
\hline \multicolumn{6}{|c|}{ Inclusion and exclusion criteria } \\
\hline Demographic variables & $\begin{array}{l}\text { Eg, age, enrolled in a university, } \\
\text { internet access, current } \\
\text { participation in a mindfulness } \\
\text { intervention }\end{array}$ & $\mathrm{x}$ & & & \\
\hline
\end{tabular}

Freiburg Mindfulness Inventory-short form Mindfulness

$\mathrm{X}$

\section{Primary Outcome}

Freiburg Mindfulness Inventory-short form Mindfulness

$\mathrm{X} \quad \mathrm{X}$

Secondary Outcomes

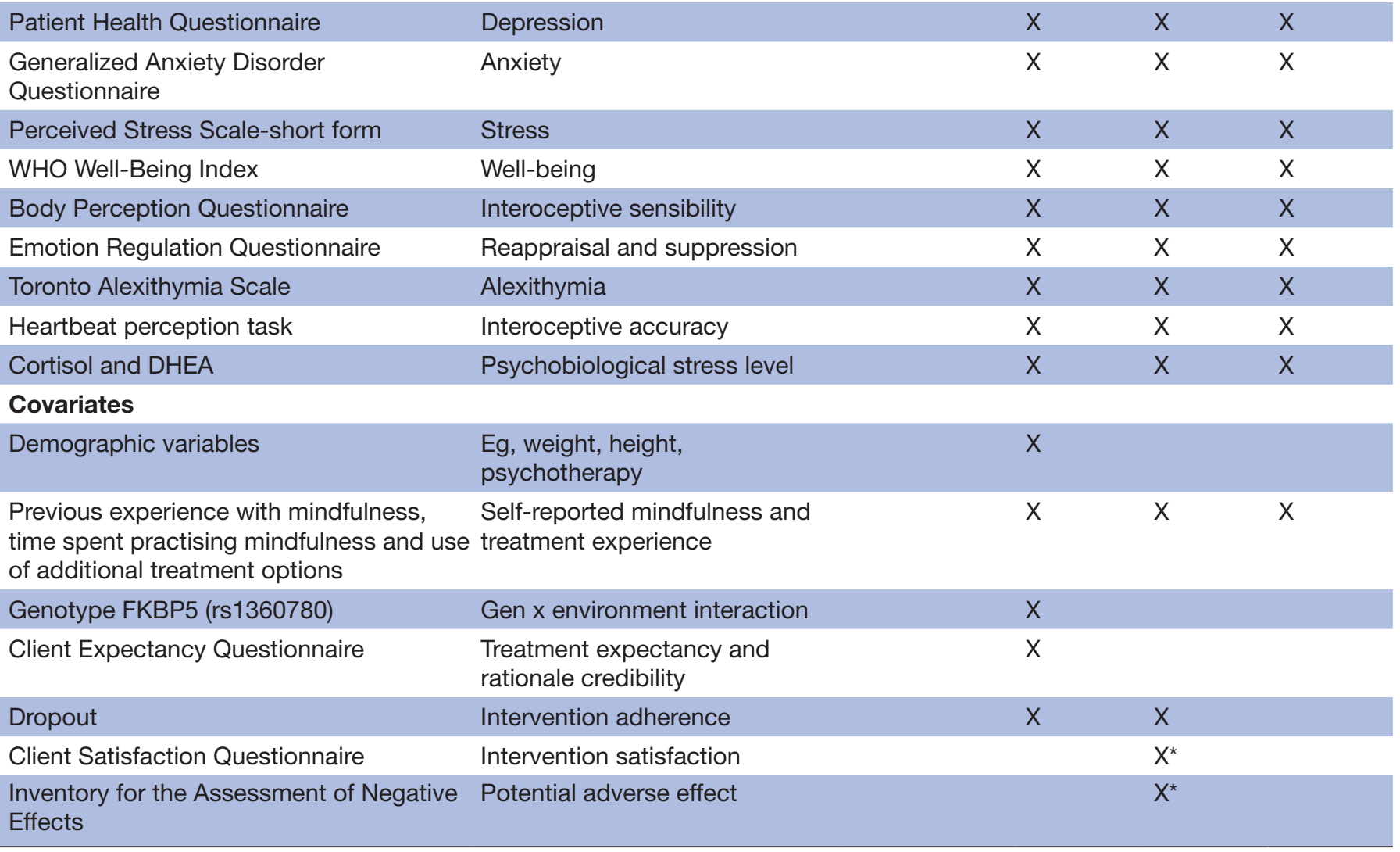

${ }^{*}$ Only for the intervention group.

DHEA, dehydroepiandrosterone.

\section{Interoceptive sensibility}

Interoceptive sensibility is assessed via the awareness subscale of the Body Perception Questionnaire (BPQ). ${ }^{119}$ It includes 45 items of individual identifications of bodily signals on a 5-point Likert scale, ranging from 'never' $(=1)$ to 'always' (=5). Calculated t scores reflect a standardised value according to a normal distribution based on a mean of 50 and a SD of 10 . Previous reliability reports exist only for the short form of the BPQ ${ }^{120}$ showing a categorical omega coefficient between 0.68 and 0.97 and a high retest reliability.

\section{Emotion regulation}

A German translation ${ }^{121}$ of the Emotion Regulation Questionnaire (ERQ $)^{122}$ is used to assess individual differences in the habitual use of two emotion regulation strategies, reappraisal and suppression. The questionnaire includes six items measuring reappraisal and four items measuring suppression. Participants are required to indicate whether they agree with each statement on a 7-point Likert scale ranging from 1 (='strongly disagree') to 7 (='strongly agree'). The ERQ demonstrates good scale score reliability for the suppression (Cronbach's Alpha $=0.76$ ) as well for the reappraisal factors (Cronbach's Alpha=0.74). ${ }^{121}$

\section{Alexithymia}

The Toronto-Alexithymia Scale (TAS-20 ${ }^{123}$; German adaptation by Kupfer $e a^{124}$ ) measures alexithymia. The questionnaire consists of 20 items rated on a 5-point Likert 
scale ( $1=$ 'strongly disagree'; $5=$ ='strongly agree') with total scores ranging from 20 to 100 , reflecting a threefactor scale: 'difficulty identifying feelings', 'difficulty describing feelings' and 'externally oriented thinking'. Higher scores on the different subscales indicate higher levels of alexithymia. The TAS-20 is a valid instrument with good internal consistency (Cronbach's Alpha of 0.85 to 0.86 ) and test-retest reliability. ${ }^{125}$

\section{Subjective side effects and adverse events}

In a survey with 195 former psychotherapy patients, 94\% stated to have experienced negative effects during or after psychotherapy. ${ }^{126}$ Consequently, Ladwig et al ${ }^{126}$ developed the Inventory for the Assessment of Negative Effects which is included to assess any changes in the experiences during or after the treatment in the social and/or work environment and whether they are attributed to the psychotherapeutic intervention. The items cover potential adverse events in the personal, intrapersonal, and social context (eg, 'emotions', 'family and friends'). Four items are rated on a 7-point bipolar scale $(-2=$ 'worse',$+3=$ ='better'), the others are rated on a 4-point scale $(0=$ 'no agreement', $3=$ 'full agreement'). The present trial uses an adapted 22-item version covering possible negative effects associated specifically with online training (eg, concerns about data protection). The original scale has demonstrated high internal consistency with a Cronbach's Alpha of $0.86 .^{126}$

\section{Intervention satisfaction and adherence}

The Client Satisfaction Questionnaire $(\mathrm{CSQ})^{127}$ is a validated 8-item tool and is used in a German version adapted for the evaluation of IMIs (ZUF-8) ${ }^{128}$ The ZUF-8 comprises eight items, each with a 4-point scale of specific response alternatives (eg, 1='quite unsatisfied', 4='very satisfied'). Good psychometric properties have been demonstrated including Cronbach's Alphas between 0.88 and 0.92. ${ }^{129}$ Additionally, qualitative feedback is assessed via a self-developed questionnaire for further optimisation of the intervention. Adherence is operationalised by the number of modules participants complete during the "per protocol" intervention period of eight weeks.

\section{Psychobiological outcomes}

We also assess psychobiological variables including the heartbeat perception task (=interoceptive accuracy) as well as hair cortisol and DHEA at all three measurement points. The FKBP5 genotype dichotomous model (CC vs. $\mathrm{CT} / \mathrm{TT}$ carriers) is only measured before the intervention and is used as a covariate in the analyses.

\section{Heartbeat perception task}

The heartbeat perception task by Schandry ${ }^{130}$ assesses the sensitivity for cardiovascular signals, namely interoceptive accuracy. Therefore, participants are instructed to listen to their own heartbeats and count them silently during different intervals. We chose a training interval of $15 \mathrm{~s}$ for participants to get familiar with the task followed by four test intervals $(25,35,45$ and $60 \mathrm{~s})$. Importantly, participants do not get any information about the lengths of these intervals. They receive start and stop signals for each interval from the investigator. After every stop signal, they have to report their counted heartbeats as well as their confidence ratings ( $1=$ 'total guess/no heartbeat awareness' to $10=$ 'complete confidence/full perception of heartbeat'). Biopac MP 150 (sampling rate $1000 \mathrm{~Hz}$ ) is used for recording the heartbeats.

\section{Hair cortisol and DHEA}

To assess the changes in the psychophysiology stress level across the time of intervention, cortisol and DHEA are used. Therefore, two strains $(\sim 3 \mathrm{~mm}$ diameter $)$ with a length of minimum $2 \mathrm{~cm}$ are obtained from the posterior vertex of each participant. Importantly, hair should be cut as close to the scalp as possible, using a fine medical scissor. The scalp hair is wrapped in aluminium foil and stored at $-20^{\circ} \mathrm{C}$ in a dry, dark place until the analyses start.

\section{Gene FKBP5}

For the investigation of a possible gen $\mathrm{x}$ environment interaction, the FKBP5 genotype is included as another psychobiological variable in the study. Therefore, samples from the buccal mucosa are taken non-invasively using buccal mucosa collection swabs (Salimetrics, UK). DNA from buccal cells is isolated using commerciallyavailable column-based purification techniques (Qiagen, Germany). DNA is tested for quality $(260 / 280 \mathrm{~nm}$ absorption) and concentration (Qubit, Thermofisher, USA). TaqMan assays for FKBP5 genotyping at position rs1360780 (T/C-allele) are performed using qPCR technology on a QuantStudio6 machine (Thermofisher, USA).

\section{Covariates}

To investigate potential effect-modifying influences, ${ }^{131}$ several sociodemographic variables are assessed: age, gender, nationality, marital status, study course and number of semesters, weight and height (for the calculation of the body mass index), previous experience with mindfulness, time spent practising mindfulness, psychotherapy experience, and use of additional treatment options (such as psychological counselling or psychotherapy). Regarding the hair analyses, we evaluate current hair colour and colouring, hair structure, and existence of permanent waves. To examine the influence of treatment expectations on outcomes, the ZUF-8 is used which has demonstrated high internal consistency $(\alpha=0.84-0.85$; CEQ) ${ }^{132}$ Higher scores represent positive expectations and credibility. Additionally, we collect data in the postmeasurement of the online survey regarding the claim of other support (coaching, psychotherapy, psychiatry, family doctor, psychotropic drugs, mindfulness training, other health training or 'StudiCare' projects). Further, if subjects participate in another kind of mindfulness training, they are asked for the format (presence, online, book, coaching). 


\section{Sample size estimation}

The sample size estimation based on a calculation of $G^{*}$ Power V. 3.1.9.2, assuming a small effect size of $f=0.15$ (consistent with $\mathrm{d}=0.3$ ) in a repeated measurement model and a comparison of two groups. Based on an $\alpha$-level of 0.05 and a power of 0.90 , the total sample should consist of 120 participants including 60 for the guided intervention group and 60 for the waitlist control group. The assumed effect size of $\mathrm{d}=0.3$ is based on the meta-analysis of Jayewardene $e t a l^{65}$ and Spijkerman et $a l^{64}$ regarding online mindfulness-based interventions.

\section{Dissemination and data processing}

The trial was registered prior to the recruitment at the WHO International Clinical Trials Registry Platform via the German Clinical Studies Trial Register (DRKS; ID: DRKS00014701). Participants received written information on study conditions, data security, participation being voluntary and the right to leave the study at any time. To confirm understanding, written consent is obtained from all participants prior to study entry. Data collection is pseudonymised and only accessed by authorised study personnel obliged to secrecy. After data collection is completed, personalised information will be deleted and all data will be completely anonymised. The results will be published in peer-reviewed journals and presented on international conferences.

\section{Statistical analyses}

All statistical analyses will be conducted according to the intention-to-treat principle. Procedures of imputation will be chosen based on patterns and mechanism of missingness (eg, by multiple imputations). Additionally, per protocol analyses will be performed to examine the impact of dropouts on the study results. The significance level for all analyses will be $p \leq 0.05$ and will be adjusted for multiple comparisons using the Holm-Bonferroni correction method.

Standardised mean differences with 95\% CIs will be calculated post-treatment and follow-up to analyse between-group effect sizes. Regression analyses will be performed as a primary method, using linear regression for dichotomous outcomes. Based on the data structure, regression analysis will be adjusted accordingly (eg, use of robust estimation or use of multilevel regression analysis in case of substantial intra-class correlation). Analysed variables will include the covariates (eg, age, gender, gene FKBP5) using path modelling.

\section{DISCUSSION}

This study protocol describes the study design of a randomised controlled trial that investigates psychobiological health-related variables in addition to the commonly used self-report data of a guided online mindfulness-focused intervention in a student sample. We assume that individuals who participate in the guided intervention will show decreased depression, anxiety, and stress levels as well as reduced alexithymia in comparison to the waitlist control group. Furthermore, we hypothesise an increase of well-being, interoceptive sensibility, and emotion regulation in the intervention group compared to the waitlist control group. Focusing on different psychobiological variables (interoceptive accuracy, hair cortisol, and DHEA), we expect similar positive effects. In order to find out more about the covariates, we also include sociodemographic data, the gene FKBP5, and expectations regarding the intervention in our analyses. Our study focuses on some aspects discussed in previous studies, aiming at combining these points here. Consequently, this study has several strengths:

\section{Combination of self-report and psychobiological measurements}

In comparison to earlier studies, our investigation includes self-report and psychobiological markers. Consequently, we use subjective as well as objective parameters to emphasise our results, meaning that especially psychobiological markers are less biased compared to the selfreport measurements. This is especially based on the research so far, showing that a combination of both is suitable to include advantages and disadvantage of both approaches. ${ }^{667133}$ Furthermore, the hair stress markers represent longitudinal markers from the last weeks or even months. ${ }^{79}$ In contrast, cortisol measurements such as salivary, plasma, or urine are time-limited and depend on changes associated with circadian rhythm regulation.

\section{Procedures to improve the adherence level}

Our proposed intervention includes different opportunities to improve adherence. This is based on the high dropout rates of $40 \%$ to $70 \%$ in different online or smartphone interventions. ${ }^{60134135}$ Firstly, we only include participants with low or moderate mindfulness in our intervention. One reason for choosing this level is a potential higher motivation and interest from participants, resulting in an assumed lower dropout rate in the intervention. However, it should be mentioned that it is only a hypothesis which is not measured in the study. Secondly, we use different modes of delivery in order to increase the adherence level of our online intervention. These modes include text, audio files, self-reflection, homework, instructions, and tips for implementing and transferring intervention components into daily life. Following the main seven intervention modules, participants also get two booster sessions which summarise and repeat the other modules before. Thus, a moderate to long-term intervention effect is obtained, and the adherence level is expected to be high. Thirdly and importantly, we include e-coaching in our training. A current study by Kvillemo et $a b^{60}$ reported that a higher contact level decreases the dropout rate and is an important option that increases the adherence level of participants. The e-coach has the task to give the participants feedback concerning the completed modules and remind them if they do not attend. Additionally, participants get the opportunity to 
contact the e-coach via the messenger system of Minddistrict. Lastly, the online mindfulness-focused intervention is tailored to the particular needs of students, which will raise the adherence level and likely enhance the effectiveness of the online intervention.

\section{Adherence level}

To explore the reasons for different adherence levels, participants answer quantitative and qualitative questions regarding the content of modules and their motivation. These responses will help us to adapt and improve the online intervention and accordingly enhance adherence.

\section{Follow-up measurements six months after randomisation}

Several studies reported no follow-up measurements. ${ }^{606} 63136$ Other studies used different intervals for the follow-up measurement after the intervention, ranging from two weeks up to six months. ${ }^{28} 4361134137$ To focus on the longitudinal effects of our intervention, we examine participants again six months after randomisation.

\section{Conclusion}

Assuming positive results of the present online mindfulness-focused intervention, it could be a helpful opportunity for universities to establish a time- and costeffective healthcare service. Given the high stress rate in the student population, the present intervention will contribute information and practices to decrease individual's stress levels as well as to improve mental health in general. Another advantage is the prevention of other upcoming mental health problems, resulting from a high stress level. Thus, this stand-alone intervention can provide advantages for users and the healthcare system. Moreover, results will have implications for researchers, healthcare providers, and public health policymakers.

Acknowledgements We thank Danielle Preuss, Katharina Peip and Ronja Gabriel for their contributions to the development of 'StudiCare Mindfulness'. Thanks to Mathias Harrer for taking care of the 'StudiCare' website and to Fanny Kählke for supporting the establishment of the study administration and assessment processes. Moreover, we like to thank our study assistants Tim Dretzler, Karoline Knauer and Francesca Mildenberger for their support in the development of the intervention, the assessment procedures and the study administration processes.

Contributors DS, AMK, DDE, HB and OP initiated this study. AMK, DS, HB and OP contributed to the design of this study. DS, AMK, CS and FW adapted the intervention content and the assessment. DS and AMK are responsible for the recruitment. AK is responsible for the analysis of the biological marker. DS wrote the draft of the manuscript. All authors contributed to the further writing of the manuscript and approved the final version of the manuscript.

Funding The project is funded by the BARMER, a major health care insurance company in Germany. BARMER had no role in study design, decision to publish or preparation of this manuscript. BARMER will not be involved in data collection, analyses, decision to publish or preparation of future papers regarding the 'StudiCare' project.

Competing interests DS, AMK, DDE, HB and OP were involved in the development of 'StudiCare Mindfulness' or its predecessor versions. AK has received fees for lectures/workshops from chambers of psychotherapists and health insurance companies. HB reports having received consultancy fees and fees for lectures/ workshops from chambers of psychotherapists and training institutes for psychotherapists in the e-mental-health context. DDE reports having received consultancy fees/served in the scientific advisory board from several companies such as Minddistrict, Lantern, Schoen Kliniken and German health insurance companies. He is a stakeholder of the Institute for health training online (GET.ON) which aims to implement scientific findings related to digital health interventions into routine care.

Patient and public involvement Patients and/or the public were involved in the design, or conduct, or reporting, or dissemination plans of this research. Refer to the Methods section for further details.

Patient consent for publication Not required.

Ethics approval All study procedures were approved by the Ethics Committee of Ulm University (application No. 48/18).

Provenance and peer review Not commissioned; externally peer reviewed.

Data availability statement No data are available. At the moment, this is only a study protocol. Consequently, there are no data that are integrated into the manuscript.

Open access This is an open access article distributed in accordance with the Creative Commons Attribution Non Commercial (CC BY-NC 4.0) license, which permits others to distribute, remix, adapt, build upon this work non-commercially, and license their derivative works on different terms, provided the original work is properly cited, appropriate credit is given, any changes made indicated, and the use is non-commercial. See: http://creativecommons.org/licenses/by-nc/4.0/.

\section{ORCID iDs}

Dana Schultchen http://orcid.org/0000-0001-5623-535X

Ann-Marie Küchler http://orcid.org/0000-0003-3305-4892

Christine Schillings http://orcid.org/0000-0002-8807-9547

Felicitas Weineck http://orcid.org/0000-0002-7377-8257

Alexander Karabatsiakis http://orcid.org/0000-0002-5822-0108

David D. Ebert http://orcid.org/0000-0001-6820-0146

Harald Baumeister http://orcid.org/0000-0002-2040-661X

Olga Pollatos http://orcid.org/0000-0002-0512-565X

\section{REFERENCES}

1 Bayram N, Bilgel N. The prevalence and socio-demographic correlations of depression, anxiety and stress among a group of university students. Soc Psychiatry Psychiatr Epidemiol 2008;43:667-72.

2 Beiter R, Nash R, McCrady M, et al. The prevalence and correlates of depression, anxiety, and stress in a sample of college students. $J$ Affect Disord 2015;173:90-6.

3 Techniker Krankenkasse. Bleib locker, Deutschland! TK-Studie zur Stresslage der Nation. Studienband der Techniker Krankenkasse, 2013. Available: https://www.tk.de/centaurus/servlet/contentblob/ 590188/Datei/115476/TK_Studienband_zur_Stressumfrage.pdf [Accessed 1 Nov 2018].

4 Bewick BM, Gill J, Mulhern B, et al. Using electronic surveying to assess psychological distress within the UK student population: a multi-site pilot investigation. EJAP 2008;4.

5 Cook LJ. Striving to help college students with mental health issues. J Psychosoc Nurs Ment Health Serv 2007;45:40-4.

6 Hintz S, Frazier PA, Meredith L. Evaluating an online stress management intervention for college students. J Couns Psychol 2015;62:137-47.

7 Stallman HM. Psychological distress in university students: a comparison with general population data. Aust Psychol 2010;45:249-57.

8 Blanco C, Okuda M, Wright C, et al. Mental health of college students and their non-college-attending Peers: results from the National epidemiologic study on alcohol and related conditions. Arch Gen Psychiatry 2008;65:1429-37.

9 Pedrelli P, Nyer M, Yeung A, et al. College students: menta health problems and treatment considerations. Acad Psychiatry 2015;39:503-11.

10 Thurber CA, Walton EA. Homesickness and adjustment in university students. J Am Coll Health 2012;60:415-9.

11 Dyrbye LN, Thomas MR, Shanafelt TD. Systematic review of depression, anxiety, and other indicators of psychologica distress among U.S. and Canadian medical students. Acad Med 2006;81:354-73.

12 Ibrahim AK, Kelly SJ, Adams CE, et al. A systematic review of studies of depression prevalence in university students. J Psychiatr Res 2013;47:391-400.

13 Krumrei EJ, Newton FB, Kim E. A Multi-Institution look at college students seeking counseling: nature and severity of concerns. $J$ College Stud Psychother 2010;24:261-83. 
14 Zivin K, Eisenberg D, Gollust SE, et al. Persistence of mental health problems and needs in a college student population. J Affect Disord 2009;117:180-5.

15 Auerbach RP, Alonso J, Axinn WG, et al. Mental disorders among college students in the world Health organization world mental health surveys. Psychol Med 2016;46:2955-70.

16 Bailer J, Schwarz D, Witthöft M, et al. Prävalenz psychischer syndrome bei Studierenden einer deutschen Universität. Psychother Psych Med 2008;58:423-9.

17 Bruffaerts R, Mortier P, Kiekens G, et al. Mental health problems in college freshmen: prevalence and academic functioning. J Affect Disord 2018;225:97-103.

18 McGorry PD, Purcell R, Goldstone S, et al. Age of onset and timing of treatment for mental and substance use disorders: implications for preventive intervention strategies and models of care. Curr Opin Psychiatry 2011;24:301-6.

19 Ramsawh HJ, Weisberg RB, Dyck I, et al. Age of onset, clinical characteristics, and 15-year course of anxiety disorders in a prospective, longitudinal, observational study. J Affect Disord 2011;132:260-4.10.1016/j.jad.2011.01.006

20 Brimstone R, Thistlethwaite JE, Quirk F. Behaviour of medical students in seeking mental and physical health care: exploration and comparison with psychology students. Med Educ 2007:41:74-83.

21 Eisenberg D, Golberstein E, Gollust SE. Help-Seeking and access to mental health care in a university student population. Med Care 2007;45:594-601.

22 Hunt J, Eisenberg D. Mental health problems and help-seeking behavior among college students. J Adolesc Health 2010;46:3-10.

$23 \mathrm{SH}$ L, Dear BF, Johnston L, et al. An Internet survey of emotional health, treatment seeking and barriers to accessing mental health treatment among Chinese-speaking international students in Australia. Counselling Psychology Quarterly 2014;27:96-108.

24 Raunic A, Xenos S. University counselling service utilisation by loca and international students and user characteristics: a review. Int $J$ Advance Counsel 2008;30:262-7.

25 Ryan ML, Shochet IM, Stallman HM. Universal online interventions might engage psychologically distressed university students who are unlikely to seek formal help. Advances in Mental Health 2010;9:73-83.

26 Ebert DD, Buntrock C, Lehr D, et al. Effectiveness of Web- and Mobile-Based treatment of subthreshold depression with Adherence-Focused guidance: a single-blind randomized controlled trial. Behav Ther 2018;49:71-83.

27 Ebert DD, Cuijpers P, Muñoz RF, et al. Prevention of mental health disorders using Internet- and Mobile-Based interventions: a narrative review and recommendations for future research. Front Psychiatry 2017;8:116.

28 Frazier P, Meredith L, Greer C, et al. Randomized controlled trial evaluating the effectiveness of a web-based stress management program among community college students. Anxiety Stress Coping 2015;28:576-86.

29 Kitzrow MA. The mental health needs of today's college students: challenges and recommendations. J Stud Aff Res Pract 2003;41.

30 Portnoy DB, Scott-Sheldon LAJ, Johnson BT, et al. Computerdelivered interventions for health promotion and behavioral risk reduction: a meta-analysis of 75 randomized controlled trials, 1988-2007. Prev Med 2008;47:3-16.

31 Andersson G, Cuijpers P, Carlbring P, et al. Guided Internet-based vs. face-to-face cognitive behavior therapy for psychiatric and somatic disorders: a systematic review and meta-analysis. World Psychiatry 2014;13:288-95.

32 Carlbring P, Andersson G, Cuijpers P, et al. Internet-Based vs. face-to-face cognitive behavior therapy for psychiatric and somatic disorders: an updated systematic review and meta-analysis. Cogn Behav Ther 2018;47:1-18.

33 Lappalainen P, Granlund A, Siltanen S, et al. Act Internet-based vs face-to-face? A randomized controlled trial of two ways to deliver acceptance and commitment therapy for depressive symptoms: an 18-month follow-up. Behav Res Ther 2014;61:43-54

34 Baños RM, Etchemendy E, Mira A, et al. Online positive interventions to promote well-being and resilience in the adolescent population: a narrative review. Front. Psychiatry 2017;8:10.

35 Chiauzzi E, Brevard J, Thurn C, et al. MyStudentBody-Stress: an online stress management intervention for college students. $J$ Health Commun 2008;13:555-72.

36 Fortson BL, Scotti JR, Chen Y-C, et al. Internet use, abuse, and dependence among students at a southeastern regional university. J Am Coll Health 2007;56:137-44.
37 Hanauer D, Dibble E, Fortin J, et al. Internet use among community college students: implications in designing healthcare interventions. J Am Coll Health 2004;52:197-202.

38 Klein B, Cook S. Preferences for e-mental health services amongst an online Australian sample? EJAP 2010;6.

39 Stallman HM, Kavanagh DJ. Development of an Internet intervention to promote wellbeing in college students. Aust Psychol 2018;53:60-7.

40 Amstadter AB, Broman-Fulks J, Zinzow H, et al. Internet-Based interventions for traumatic stress-related mental health problems: a review and suggestion for future research. Clin Psychol Rev 2009;29:410-20.

41 Buntrock C, Ebert DD, Lehr D, et al. Effect of a web-based guided self-help intervention for prevention of major depression in adults with subthreshold depression. JAMA 2016;315:1854-63.

42 Josephine K, Josefine L, Philipp D, et al. Internet- and mobilebased depression interventions for people with diagnosed depression: a systematic review and meta-analysis. J Affect Disord 2017;223:28-40.

43 Nguyen-Feng VN, Greer CS, Frazier P. Using online interventions to deliver college student mental health resources: evidence from randomized clinical trials. Psychol Serv 2017;14:481-9.

44 Olthuis JV, Watt MC, Bailey K, et al. Therapist-supported Internet cognitive behavioural therapy for anxiety disorders in adults. Cochrane Database Syst Rev 2015;3:CD011565.

45 Harrer M, Adam SH, Baumeister $\mathrm{H}$, et al. Internet interventions for mental health in university students: a systematic review and metaanalysis. Int J Methods Psychiatr Res 2018:e1759.

46 Andersson G. Internet-Delivered psychological treatments. Annu Rev Clin Psychol 2016;12:157-79.

47 Bishop SR. What do we really know about mindfulness-based stress reduction? Psychosom Med 2002;64:71-83.

48 Kabat-Zinn J. Mindfulness-Based interventions in context: past, present, and future. Clin Psychol Sci Prac 2003;10:144-56.

49 Kabat-Zinn J. Full catastrophe living: using the wisdom of your body and mind to face stress, pain, and illness. New York, NY: Bantam Books, 2009

50 Dimidjian S, Linehan MM. Mindfulness Practice. In: O'Donohue WT, Fisher JE, eds. General principles and empirically supported techniques of cognitive behavior therapy. Hoboken: John Wiley \& Sons Inc, 2009: 425-34.

51 Brown KW, Ryan RM. The benefits of being present: mindfulness and its role in psychological well-being. J Pers Soc Psychol 2003;84:822-48.

52 Chiesa A, Serretti A. Mindfulness-based stress reduction for stress management in healthy people: a review and meta-analysis. $J$ Altern Complement Med 2009;15:593-600.

53 Chiesa A, Serretti A. A systematic review of neurobiological and clinical features of mindfulness meditations. Psychol Med 2010;40:1239-52.

54 Eberth J, Sedlmeier P. The effects of mindfulness meditation: a meta-analysis. Mindfulness 2012;3:174-89.

55 Godfrin KA, van Heeringen C. The effects of mindfulness-based cognitive therapy on recurrence of depressive episodes, mental health and quality of life: a randomized controlled study. Behav Res Ther 2010;48:738-46.

56 Hofmann SG, Sawyer AT, Witt AA, et al. The effect of mindfulnessbased therapy on anxiety and depression: a meta-analytic review. $J$ Consult Clin Psychol 2010;78:169-83.

57 Keng S-L, Smoski MJ, Robins CJ. Effects of mindfulness on psychological health: a review of empirical studies. Clin Psychol Rev 2011;31:1041-56.

58 Strauss C, Cavanagh K, Oliver A, et al. Mindfulness-based interventions for people diagnosed with a current episode of an anxiety or depressive disorder: a meta-analysis of randomised controlled trials. PLoS One 2014;9:e96110.

59 Wahbeh H, Svalina MN, Oken BS. Group, One-on-One, or Internet? preferences for mindfulness meditation delivery format and their predictors. MEDJ 2014;1:66-74.

60 Kvillemo P, Brandberg Y, Bränström R. Feasibility and outcomes of an Internet-based mindfulness training program: a pilot randomized controlled trial. JMIR Ment Health 2016;3:e33.

61 Mak WWS, Chio FHN, Chan ATY, et al. The efficacy of Internetbased mindfulness training and cognitive-behavioral training with telephone support in the enhancement of mental health among college students and young working adults: randomized controlled trial. J Med Internet Res 2017;19:e84.

62 Cavanagh K, Strauss C, Cicconi F, et al. A randomised controlled trial of a brief online mindfulness-based intervention. Behav Res Ther 2013;51:573-8. 
63 Cavanagh K, Churchard A, O'Hanlon P, et al. A randomised controlled trial of a brief online Mindfulness-Based intervention in a non-clinical population: replication and extension. Mindfulness 2018:9:1191-205

64 Spijkerman MPJ, Pots WTM, Bohlmeijer ET. Effectiveness of online mindfulness-based interventions in improving mental health: a review and meta-analysis of randomised controlled trials. Clin Psychol Rev 2016;45:102-14.

65 Jayawardene WP, Lohrmann DK, Erbe RG, et al. Effects of preventive online mindfulness interventions on stress and mindfulness: a meta-analysis of randomized controlled trials. Preventive Medicine Reports 2017:5:150-9.

66 Döring N, Bortz J. Forschungsmethoden und evaluation in den Sozial- und Humanwissenschaften. Berlin, Heidelberg: Springer Berlin Heidelberg, 2016.

67 Garfinkel SN, Seth AK, Barrett AB, et al. Knowing your own heart: distinguishing interoceptive accuracy from interoceptive awareness. Biol Psychol 2015;104:65-74.

68 Herbert BM, Herbert C, Pollatos O. On the relationship between interoceptive awareness and alexithymia: is interoceptive awareness related to emotional awareness? J Pers 2011;79:1149-75.

69 Herbert BM, Herbert C, Pollatos O, et al. Effects of short-term food deprivation on interoceptive awareness, feelings and autonomic cardiac activity. Biol Psychol 2012;89:71-9.

70 Herbert BM, Pollatos O. Attenuated interoceptive sensitivity in overweight and obese individuals. Eat Behav 2014;15:445-8.

71 Herbert BM, Pollatos O, Schandry R. Interoceptive sensitivity and emotion processing: an EEG study. Int J Psychophysiol 2007;65:214-27.

72 Schulz A, Vögele C. Interoception and stress. Front Psychol 2015;6:993.

73 Dunn BD, Dalgleish T, Ogilvie AD, et al. Heartbeat perception in depression. Behav Res Ther 2007:45:1921-30.

74 Parkin L, Morgan R, Rosselli A, et al. Exploring the relationship between mindfulness and cardiac perception. Mindfulness 2014:5:298-313.

75 Bornemann B, Singer T. Taking time to feel our body: steady increases in heartbeat perception accuracy and decreases in alexithymia over 9 months of contemplative mental training. Psychophysiology 2017;54:469-82.

76 Fischer D, Messner M, Pollatos O. Improvement of interoceptive processes after an 8 -Week body scan intervention. Front Hum Neurosci 2017:11:452.

77 Meyer JS, Novak MA. Minireview: hair cortisol: a novel biomarker of hypothalamic-pituitary-adrenocortical activity. Endocrinology 2012;153:4120-7.

78 Jogems-Kosterman BJM, de Knijff DWW, Kusters R, et al. Basal cortisol and DHEA levels in women with borderline personality disorder. J Psychiatr Res 2007;41:1019-26.

79 Russell E, Koren G, Rieder M, et al. Hair cortisol as a biological marker of chronic stress: current status, future directions and unanswered questions. Psychoneuroendocrinology 2012;37:589-601.

80 Van Uum SHM, Sauvé B, Fraser LA, et al. Elevated content of cortisol in hair of patients with severe chronic pain: a novel biomarker for stress. Stress 2008;11:483-8.

81 Brand S, Holsboer-Trachsler E, Naranjo JR, et al. Influence of mindfulness practice on cortisol and sleep in long-term and shortterm meditators. Neuropsychobiology 2012;65:109-18.

82 Iglesias S, Jacobsen D, Gonzalez D, et al. Hair cortisol: a new tool for evaluating stress in programs of stress management. Life Sci 2015;141:188-92.

83 Schultchen D, Messner M, Karabatsiakis A, et al. Effects of an 8-Week body scan intervention on individually perceived psychological stress and related steroid hormones in hair. Mindfulness 2019;10:2532-43.

84 Bränström R, Kvillemo P, Brandberg Y, et al. Self-report mindfulness as a mediator of psychological well-being in a stress reduction intervention for cancer patients--a randomized study. Ann Behav Med 2010;39:151-61.

85 Cash E, Salmon P, Weissbecker I, et al. Mindfulness meditation alleviates fibromyalgia symptoms in women: results of a randomized clinical trial. Ann Behav Med 2015;49:319-30.

86 Jung HY, Lee H, Park J. Comparison of the effects of Korean mindfulness-based stress reduction, walking, and patient education in diabetes mellitus. Nurs Health Sci 2015;17:516-25.

87 Klatt MD, Buckworth J, Malarkey WB. Effects of low-dose mindfulness-based stress reduction (MBSR-ld) on working adults. Health Educ Behav 2009;36:601-14.
88 Tang Y-Y, Ma Y, Wang J, et al. Short-Term meditation training improves attention and self-regulation. Proc Natl Acad Sci U S A 2007;104:17152-6.

89 Witek-Janusek L, Albuquerque K, Chroniak KR, et al. Effect of mindfulness based stress reduction on immune function, quality of life and coping in women newly diagnosed with early stage breast cancer. Brain Behav Immun 2008;22:969-81.

90 Ritsner M, Gibel A, Maayan R, et al. Cortisol/ dehydroepiandrosterone ratio and responses to antipsychotic treatment in schizophrenia. Neuropsychopharmacology 2005;30:1913-22

91 Kahl KG, Bens S, Ziegler K, et al. Cortisol, the cortisoldehydroepiandrosterone ratio, and pro-inflammatory cytokines in patients with current major depressive disorder comorbid with borderline personality disorder. Biol Psychiatry 2006;59:667-71.

92 Goodyer IM, Herbert J, Tamplin A. Psychoendocrine antecedents of persistent first-episode major depression in adolescents: a community-based longitudinal enquiry. Psychol Med 2003;33:601-10.

93 Cruess DG, Antoni MH, Kumar M, et al. Cognitive-Behavioral stress management buffers decreases in dehydroepiandrosterone sulfate (DHEA-S) and increases in the cortisol/DHEA-S ratio and reduces mood disturbance and perceived stress among HIV-seropositive men. Psychoneuroendocrinology 1999;24:537-49.

94 Young AH, Gallagher P, Porter RJ. Elevation of the cortisoldehydroepiandrosterone ratio in drug-free depressed patients. AJP 2002;159:1237-9.

95 Ising M, Maccarrone G, Brückl T, et al. Fkbp5 gene expression predicts antidepressant treatment outcome in depression. Int $\mathrm{J} \mathrm{Mol}$ Sci 2019;20:485

96 Koenig AM, Ramo-Fernández L, Boeck C, et al. Intergenerational gene $\times$ environment interaction of FKBP5 and childhood maltreatment on hair steroids. Psychoneuroendocrinology 2018:92:103-12.

97 Baumeister H, Reichler L, Munzinger M, et al. The impact of guidance on Internet-based mental health interventions - a systematic review. Internet Interventions 2014;1:205-15.

98 Kuechler A-M, Schultchen D, Ebert DD, et al. StudiCare mindfulness - study protocol of a randomized controlled trial to evaluate an Internet-based intervention for college students with no vs on demand guidance. BMC Trials submitted.

99 Schulz KF, Altman DG, Moher D, et al. Consort 2010 statement: updated guidelines for reporting parallel group randomised trials. BMJ 2010;340:c332.

100 Proudfoot J, Klein B, Barak A, et al. Establishing guidelines for executing and reporting Internet intervention research. Cogn Behav Ther 2011;40:82-97.

101 Chan A-W, Tetzlaff JM, Altman DG, et al. Spirit 2013 statement: defining standard protocol items for clinical trials. Ann Intern Med 2013;158:200-7.

102 The WHO World Mental Health International College Student (WMH-ICS) Initiative. College student survey. Available: https:// www.hcp.med.harvard.edu/wmh/college_student_survey.php [Accessed 05 Oct 2018]

103 Caring Universities. Caring Universities - e-Mental Health interventions for students. Available: https://caring-universities. com/ [Accessed 05 Oct 2019].

104 Walach H, Buchheld N, Buttenmüller V, et al. Measuring mindfulness - the Freiburg mindfulness inventory (FMI). Pers Individ Dif 2006;40:1543-55.

105 Hayes SC, Strosahl KD, Wilson KG. Acceptance and commitment therapy: an experiential approach to behavior change. New York, NY: Guilford Press, 1999

105 Kabat-Zinn J. Full catastrophe living: using the wisdom of your body and mind to face stress, pain, and illness. New York: Bantam Dell, 2009.

107 Kaluza G. Stressbewältigung: Trainingsmanual Zur psychologischen Gesundheitsförderung. 2nd edn. Berlin: Heidelberg: Springer-Verlag Berlin Heidelberg, 2013.

108 Kuechler A-M, Peip K, Preuss D, et al. Efficacy of the internetbased intervention "StudiCare Mindfulness" for college students: A randomized controlled trial in preparation..

109 Walach H, Buchheld N, Buttenmüller V, et al. Empirische Erfassung Der Achtsamkeit-Die Konstruktion des Freiburger Fragebogens Zur Achtsamkeit (FFA) und weitere Validierungsstudien. Schweizerische Zeitschrift für Psychologie und ihre Anwendungen 2004:729-72.

110 Heidenreich T, Ströhle G, Michalak J. Achtsamkeit: Konzeptuelle Aspekte und Ergebnisse zum Freiburger Achtsamkeitsfragebogen. Verhaltenstherapie 2006;16:33-40.

111 Kroenke K, Spitzer RL. The PHQ-9: a new depression diagnostic and severity measure. Psychiatr Ann 2002;32:509-15. 
112 Kroenke K, Spitzer RL, Williams JBW. The PHQ-9. J Gen Intern Med 2001;16:606-13.

113 Spitzer RL, Kroenke K, Williams JBW, et al. A brief measure for assessing generalized anxiety disorder: the GAD-7. Arch Intern Med 2006;166:1092-7.

114 Löwe B, Decker O, Müller S, et al. Validation and standardization of the generalized anxiety disorder screener (GAD-7) in the general population. Med Care 2008;46:266-74.

115 Cohen S, Williamson G. Perceived Stress in a Probability Sample of the United States. In: Spacapan S, Oskamp S, eds. The social psychology of health: Claremont Symposium on applied social psychology. Newbury Park, CA: Sage, 1988: 31-68.

116 Warttig SL, Forshaw MJ, South J, et al. New, normative, Englishsample data for the short form perceived stress scale (PSS-4). J Health Psychol 2013;18:1617-28.

117 World Health Organization. World Health organization info package: mastering depression in primary care. World Health Organization, Regional Office for Europe, Psychiatric Research Unit: Frederiksborg, 1998.

118 Topp CW, Østergaard SD, Søndergaard S, et al. The WHO-5 well-being index: a systematic review of the literature. Psychother Psychosom 2015;84:167-76.

119 Porges SW. Fragebogen Zur Körperwahrnehmung, 19932015. Available at. Available: https://static1.squarespace.com/static/ 5c1d025fb27e390a78569537/t/5cc07b81ee6eb072574b3620/ 1556118401872/German+SF+updated+7-17.pdf [Accessed 02 Nov 2019].

120 Cabrera A, Kolacz J, Pailhez G, et al. Assessing body awareness and autonomic reactivity: factor structure and psychometric properties of the body perception Questionnaire-Short form (BPQSF). Int J Methods Psychiatr Res 2018;27:e1596.

121 Abler $\mathrm{B}$, Kessler $\mathrm{H}$. Emotion regulation questionnaire - Eine deutschsprachige Fassung des ERQ von gross und John. Diagnostica 2009;55:144-52.

122 Gross JJ, John OP. Individual differences in two emotion regulation processes: implications for affect, relationships, and well-being. $J$ Pers Soc Psychol 2003;85:348-62.

123 Bagby RM, Parker JD, Taylor GJ. The twenty-item Toronto Alexithymia Scale--I. Item selection and cross-validation of the factor structure. J Psychosom Res 1994;38:23-32.
124 Kupfer J, Brosig B, Brähler E. Toronto-Alexithymie-Skala-26. Deutsche Version. Manual. Göttingen: Hogrefe 2001.

125 Parker JDA, Taylor GJ, Bagby RM. The 20-Item Toronto Alexithymia scale. J Psychosom Res 2003:55:269-75.

126 Ladwig I, Rief W, Nestoriuc Y. Welche Risiken und Nebenwirkungen hat Psychotherapie? - Entwicklung des Inventars zur Erfassung Negativer Effekte von Psychotherapie (INEP). Verhaltenstherapie 2014;24:252-63.

127 Larsen DL, Attkisson CC, Hargreaves WA, et al. Assessment of client/patient satisfaction: development of a general scale. Eval Program Plann 1979;2:197-207.

128 Boß L, Lehr D, Reis D, et al. Reliability and validity of assessing user satisfaction with web-based health interventions. J Med Internet Res 2016;18:e234.

128 Kriz D, Nübling R, Steffanowski A, et al. Patientenzufriedenheit: Psychometrische Reanalyse des ZUF-8. DRV-Schriften, Band;77:84-5. Berlin: Deutsche Rentenversicherung Bund 2008.

130 Schandry R. Heart beat perception and emotional experience. Psychophysiology 1981;18:483-8.

131 Ebert DD, Gollwitzer M, Riper H, et al. For whom does it work? moderators of outcome on the effect of a transdiagnostic Internetbased maintenance treatment after inpatient psychotherapy: randomized controlled trial. J Med Internet Res 2013;15:e191.

132 Devilly GJ, Borkovec TD. Psychometric properties of the credibility/expectancy questionnaire. J Behav Ther Exp Psychiatry 2000;31:73-86.

133 Stalder T, Steudte S, Alexander N, et al. Cortisol in hair, body mass index and stress-related measures. Biol Psychol 2012;90:218-23.

134 Glück TM, Maercker A. A randomized controlled pilot study of a brief web-based mindfulness training. BMC Psychiatry 2011;11:175.

135 Howells A, Ivtzan I, Eiroa-Orosa FJ. Putting the 'app' in Happiness: A Randomised Controlled Trial of a Smartphone-Based Mindfulness Intervention to Enhance Wellbeing. J Happiness Stud 2016;17:163-85.

136 Bailey NW, Nguyen J, Bialylew E, et al. Effect on Well-Being from an Online Mindfulness Intervention: "Mindful in May". Mindfulness2018;9:1637-47.

136 Querstret D, Cropley M, Fife-Schaw C. The effects of an online mindfulness intervention on perceived stress, depression and anxiety in a non-clinical sample: a randomised Waitlist control trial. Mindfulness 2018;9:1825-36. 